\title{
Proposta de dinamização da prática de revisão de conteúdos no ensino Fundamental ii através do uso da Ferramenta Kahoot
}

\author{
Bianca Joaquim Albuquerque de Melo (MPNTDE | UniCarioca) \\ Bruno de Sousa Vieira (MPNTDE | UniCarioca) \\ Thalita Martins Rocha (MPNTDE | UniCarioca) \\ Bianca Martins (NUCAP | MPNTDE | UniCarioca | PUC-Rio) \\ Victor Gonçalves Freitas (NUCAP | MPNTDE | UniCarioca)
}

\begin{abstract}
Resumo
Propõe-se, através da presente pesquisa, identificar possibilidades de apropriação do Kahoot, uma ferramenta educacional baseada em jogos, visando dinamizar a prática de revisão de conteúdos no Ensino Fundamental II. Embora comum em diversos ambientes escolares, tal prática ainda porta características oriundas de modelos antigos de educação, que têm sido criticados quanto a sua significância e eficiência na formação dos indivíduos. Neste artigo, apresentamos a ferramenta Kahoot e sugestões de seu uso para a revisão de conteúdos. A metodologia aplicada para tal teve por base o uso da ferramenta Mapa da Empatia, que foi elaborada com base em entrevistas realizadas com um grupo de seis professores. A intenção foi identificar aspectos importantes para tornar a prática de revisão mais dinâmica, prazerosa e relevante para alunos do Ensino Fundamental II. Por fim, identificamos algumas oportunidades de aprimoramento da prática de revisão com a utilização do Kahoot que se alinham às necessidades desses professores.
\end{abstract}

Palavras-chave: Prática pedagógica; Tecnologias digitais; Revisão; Ensino-aprendizagem.

\begin{abstract}
The goal of this research is to identify possibilities to use Kahoot, a game-based learning platform, in the classroom aiming to make content review practices more dynamic for Elementary School students. Although common in many school settings, such practices still carry characteristics from older educational models, some of which have been criticized for their significance and efficiency. In this article, we present the platform Kahoot and propose suggestions applied to content review. The methodology applied was based on the use of an Empathy Map that was made based on the answers obtained from an interview with a group of six teachers, with the intention to identify important aspects to make content review a more dynamic, enjoyable and relevant practice for Elementary School students. Finally, we have identified some opportunities to improve such practices with the use of Kahoot and that are also aligned with the needs of those teachers.
\end{abstract}

Keywords: Education, Digital technology, Content review, Teaching/learning.

\section{Introdução}

Com a popularização das tecnologias digitais, alunos e professores dispõem de amplo acesso a notícias, ferramentas e conteúdos disponíveis na internet. Tendo em vista que tais tecnologias já se encontram vastamente incorporadas à vida cotidiana, sua utilização é fundamental para o oferecimento de processos de aprendizagem mais dinâmicos e significativos.

A utilização de tecnologias digitais na educação demanda uma mudança de posicionamento dos docentes, visando incorporar de forma significativa esse aspecto que está cada vez mais inserido em nosso cotidiano. Para que tal processo ocorra de forma bem sucedida, há a necessidade dos educadores adotarem as tecnologias digitais como ferramentas capazes de oferecer suporte às reflexões inerentes ao processo educativo e também visando aumentar a interatividade e o engajamento dos alunos. Ainda há desafios não apenas para o amplo uso de tecnologia no ensino, mas também no que tange a sua utilização, possibilitando processos de aprendizagem mais ativos, participativos e significativos (ALVES et al., 2013). 
Conforme Santaella (2013), as tecnologias ubíquas - como os dispositivos móveis de conexão contínua - contribuem para a formação de leitores providos de habilidades cognitivas cada vez mais híbridas e cada vez mais ricas. Aproximando este desafio ao campo da educação, a autora cita Balestrini (2010, p. 35):

É provável que, do ponto de vista educativo, mediar, na era das tecnologias digitais, implique enfrentar o desafio de se mover com engenhosidade entre a palavra e a imagem, entre o livro e os dispositivos digitais, entre a emoção e a reflexão, entre o racional e o intuitivo. Talvez o caminho seja o da integração crítica, do equilíbrio na busca de propostas inovadoras, divertidas, motivadoras e eficazes. (Balestrini, 2010, p. 35; apud Santaella, 2013, p. 27)

Santaella (2013) comenta que, em vez de substituir os processos formais de ensino, a aprendizagem ubíqua deve ser vista um complemento desses processos. E quem tem a ganhar com essa complementaridade é o ser humano em formação por conta do acréscimo de possibilidades que a ubiquidade lhe abre. Por isso mesmo, mergulhar no jogo das complementaridades tecnológicas deveria ser o mote para os educadores em prol de formas de aprendizagem que estejam em sintonia os preceitos do nosso tempo.

Com base nas colocações aqui expostas, identifica-se a oportunidade de propor metodologias mais dinâmicas e com uso de tecnologias móveis que possam ser adaptadas e incorporadas às práticas educacionais já existentes para auxiliar o processo de ensino-aprendizagem. Neste artigo, apresentamos a ferramenta Kahoot e suas possibilidades de utilização para revisar conteúdos no Ensino Fundamental II, segmento formado por sujeitos hábeis na utilização de linguagens tecnológicas dinâmicas e que promovem a socialização e estimulam a participação no processo de ensino-aprendizagem.

\section{Revisão de literatura e apresentação do Kahoot}

Ao longo da última década, o acesso aos meios tecnológicos foi facilitado em diversas vertentes, de modo que tal fenômeno se refletiu nas escolas (WERNER, 2015). Segundo Formiga (2015), a utilização de tecnologia em suas diversas formas, no ambiente escolar, pode proporcionar aos alunos novas experiências, possibilitando novos meios para a construção de conhecimento. Tal prática também traz benefícios aos docentes, pois, conforme Almeida (2015), ao utilizar tais recursos o professor se depara com outras possibilidades em sua própria prática. Neste artigo, enfatizamos a utilização da plataforma de aprendizagem Kahoot.

O Kahoot é uma ferramenta gratuita projetada para avaliação da aprendizagem através da gamificação (JUNIOR, 2017). Dentre as definições do termo gamificação, Deterding et al. (2011) a descrevem como a técnica de elaborar artefatos com elementos e características frequentemente presentes em jogos, mas cujas finalidades extrapolem o entretenimento.

Todor (2015) comenta que a gamificação é um processo que visa à apropriação dos princípios e mecânica dos games para propósitos diferentes. Sua função seria intensificar o envolvimento dos usuários, melhorar a qualidade destas interações e ainda promover a autoexpressão e o aprendizado. Sendo baseada nos games, a gamificação também estimula o desejo de competição com base em tarefas, missões ou atividades específicas. Alguns projetos incluem premiação como medalhas, moedas virtuais, gráficos comparativos, etc.

Tendo em vista que o Kahoot foi desenvolvido visando aplicar elementos de jogos com finalidade educacional, sua proposta está de acordo com o conceito de gamificação.

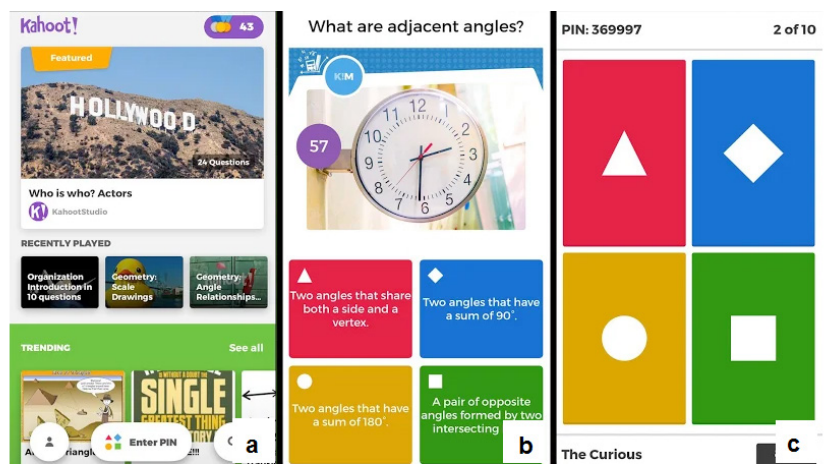

Figura 1: Algumas telas do Aplicativo Kahoot: a tela de início do app (a), a tela contendo o enunciado da pergunta e suas respectivas alternativas (b) e a tela de resposta (c). Imagens retiradas de $<\mathrm{http}$ ://kahoot.com $>$ e editadas por Bianca Melo. 
A ferramenta foi elaborada para oferecer uma alternativa menos custosa aos clickers, ferramentas populares nas universidades estadunidenses para estimular a participação dos alunos nas aulas com turmas muito grandes. Os clickers são ferramentas interativas e baseiam-se em respostas rápidas às perguntas objetivas elaboradas pelos professores das disciplinas. As perguntas objetivas são exibidas no projetor multimídia ao longo de uma aula para que os alunos respondam em tempo real, através de um dispositivo específico.

Kaleta e Joosten (2007) apontam em sua pesquisa sobre esse tipo de sistema que, embora professores e alunos tenham considerado a adoção dos clickers durante as aulas como algo positivo, a curva de aprendizagem para utilizar a ferramenta e sua implementação são aspectos negativos de sua utilização, além do alto custo de aquisição e da necessidade de infraestrutura para seu funcionamento, o que torna a utilização de clickers pouco flexível.

Dellos (2015) atribui ao Kahoot a mesma classificação atribuída aos clickers, como um Student Response System, ou seja, um sistema que possibilita que os alunos interajam mais durante as aulas respondendo a questões levantadas pelos professores. Em comparação aos clickers, o Kahoot se apresenta como uma alternativa mais vantajosa por diversos motivos, como a facilidade de utilização em diversas plataformas e também ao fato de não depender da aquisição de dispositivos específicos para que seja utilizado, necessitando apenas que os aparelhos utilizados tenham conexão à internet no momento de realização das atividades. Portanto, é possível implementar a utilização do Kahoot em uma gama mais diversificada de ambientes, sejam eles laboratórios de informática ou em salas de aula com estruturas tradicionais, utilizando os dispositivos móveis dos próprios alunos.

Outro aspecto positivo apontado por Dellos (2015) é a facilidade que os alunos têm de acessar as tarefas, não sendo necessária a criação de um nome de usuário e senha para a realização das atividades. Todavia, é imprescindível que os professores criem uma conta no site para que possam criar os questionários e atividades, além de obter acesso às estatísticas de desempenho dos alunos. Tais estatísticas são disponibilizadas em planilhas que oferecem dados detalhados de desempenho nos âmbitos individual e coletivo.

Embora a ferramenta ainda não esteja disponível em português, já existem quase 120 mil atividades disponíveis em português no banco de atividades do Kahoot, de um total superior a 27 milhões em todo o mundo, o que evidencia que a ferramenta tem sido adotada tanto no Brasil quanto em outros países para diversas finalidades educacionais.

As atividades oferecidas por essa ferramenta possuem quatro modalidades: o Kahoot clássico, que consiste em um jogo de perguntas e respostas com até quatro alternativas, sendo uma delas obrigatoriamente correta; o Discussion, uma funcionalidade que visa o apoio às discussões em sala de aula, também dispondo de até quatro alternativas, sem que nenhuma delas seja marcada como certa ou errada; o Survey, que possibilita a realização de enquetes na sala de aula; e o Jumble, utilizado para atividades que envolvam ordenação de alternativas. O professor cadastrado no site pode criar quantas atividades forem necessárias, em diferentes modalidades, sendo necessário definir de antemão o tipo de atividade. Não é possível mesclar diferentes modalidades em uma mesma tarefa.

No escopo desta pesquisa, focamos na modalidade mais utilizada, o Kahoot Clássico. Apresentaremos a seguir alguns exemplos de telas de realização de atividade na ferramenta, tanto da perspectiva do professor quanto dos alunos.

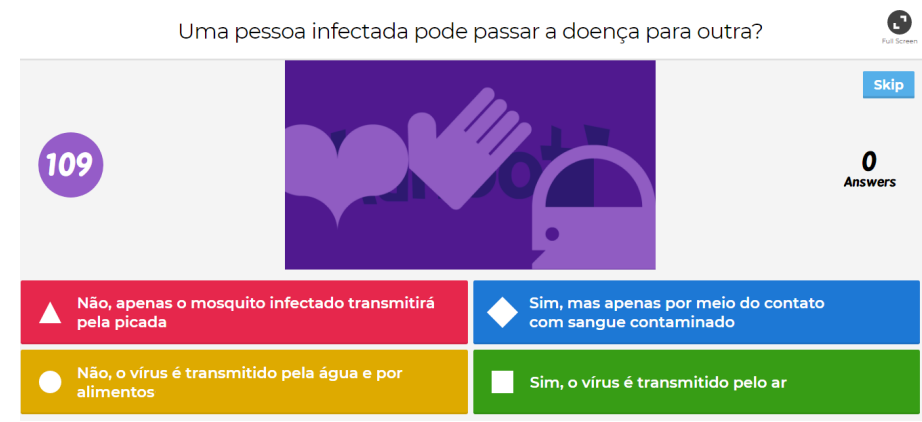

Figura 2: Página que contém o enunciado da pergunta e as alternativas em uma atividade em andamento no Kahoot. Este é o conteúdo que aparece no projetor, conectado à máquina do professor. Fonte: Bianca Melo. 
A Figura 2 mostra um exemplo de tela que é exibida em todas as perguntas de qualquer atividade realizada no Kahoot Clássico. É permitida a inserção de no máximo quatro alternativas para cada pergunta, e é possível que o professor determine, de antemão, um limite de tempo para que cada pergunta seja respondida. Tal limite varia de 10 segundos até 2 minutos e é ajustável para cada pergunta. Portanto, perguntas mais simples e com alternativas mais curtas podem ter um limite de tempo menor, enquanto questões mais complexas podem ser configuradas para aceitar respostas em uma janela de tempo mais extensa. Nesta tela, também há informações sobre a quantidade de participantes que já responderam à pergunta, atualizada em tempo real, e a opção de pular. Tal opção é útil por questões de adaptação, quando se utiliza uma atividade que trabalha alguns conteúdos ainda não vistos em sala. Desse modo, o professor pode pular as perguntas que não se alinham ao seu programa de ensino.
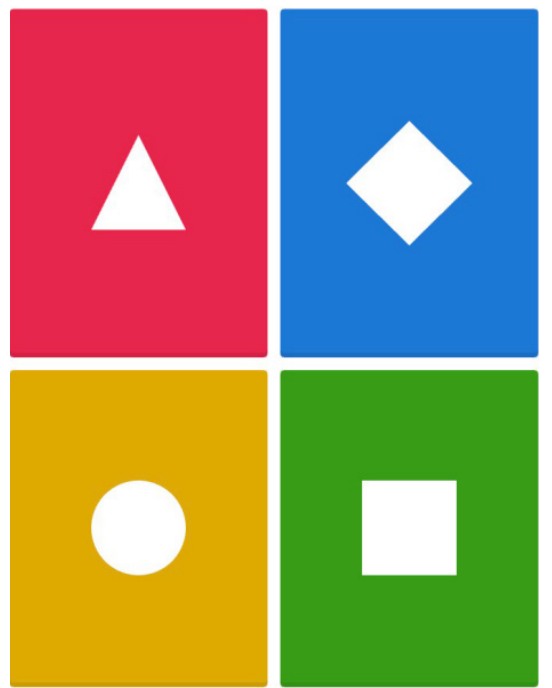

Figura 3: Tela visível no dispositivo do aluno (neste caso, visão de um dispositivo móvel). Para responder, deve-se clicar em uma das quatro opções. Fonte: Bianca Melo.

Enquanto a tela apresentada na Figura 2 fica disponível no projetor, uma tela diferente (Figura 3), que contém apenas os ícones correspondentes às respostas, fica disponível nos dispositivos que cada aluno utiliza para jogar, até que ele responda e seja direcionado para uma tela de espera enquanto aguarda a solução, que é revelada apenas quando todos os participantes da atividade respondem ou quando o tempo para aceite de respostas acaba. O Kahoot Clássico trabalha com múltipla escolha e a interface adotada pelo sistema tem a finalidade de possibilitar a identificação dos itens da resposta, facilitada pelo uso de cores fortes e de alto contraste entre o conjunto e de formas de fácil distinção entre si. A cada alternativa é designada uma combinação corforma, de modo que os alunos, ao responderem, localizem mais rapidamente a alternativa desejada a partir de uma associação mais simples.

É importante ressaltar que os participantes não são notificados de imediato se acertaram ou erraram a questão. Tal feedback só é dado após a revelação da solução que, como exposto anteriormente, está atrelada à passagem de tempo ou à resposta de todos os jogadores.

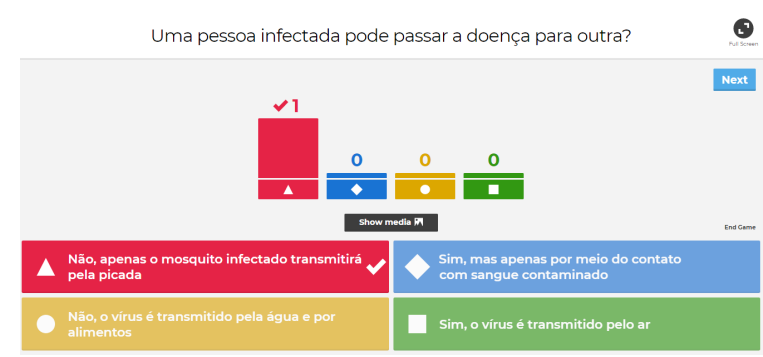

Figura 4: Exemplo de tela de exibição da resposta. A resposta correta é indicada pelo símbolo branco à direita da alternativa, que também é destacada pela cor, enquanto as alternativas incorretas assumem tons mais claros e "apagados". Além disso, apresentam-se estatísticas sobre quantidades de acertos e erros em cada questão. Fonte: Bianca Melo. 
A Figura 4 mostra a tela de apresentação da resposta correta. Do ponto de vista pedagógico, este é um momento de grande importância na realização da atividade, pois é possível identificar algumas das dúvidas através das respostas incorretas e, a partir disso, intervir com mais esclarecimentos sobre o assunto, durante a atividade. O site disponibiliza as estatísticas de respostas para que os professores possam analisar posteriormente e de forma mais agregadora, no contexto de todas as questões apresentadas durante a atividade. Todavia, isso não exclui a possibilidade de aproveitar o momento pedagógico de trabalhar na compreensão de um determinado conceito logo após a resposta.

\section{Metodologia}

A proposta deste trabalho é avaliar a pertinência e relevância do uso da ferramenta Kahoot no Ensino Fundamental II. Para tal, escolhemos realizar uma pesquisa qualitativa com professores deste segmento com base na ferramenta Mapa da Empatia, de modo a compreender as principais necessidades desses profissionais. Após, oferecemos algumas sugestões de uso da ferramenta que visam atender a tais demandas percebidas pelos professores entrevistados.

O Mapa da Empatia é uma ferramenta usada por Designers e gestores de negócios para melhor compreender o perfil dos usuários ou praticantes de um cenário específico, ajudando a entender problemas e necessidades dessas pessoas para, assim, repensar e redesenhar problemas utilizando como foco a empatia. A ferramenta pauta-se em perguntas semiestruturadas com vistas a elaborar, após a análise delas, um perfil genérico, ou seja, a criação de uma pessoa (persona) fictícia que representa um determinado segmento ou grupo de pessoas. Por esse motivo, a ferramenta é efetiva para empreender um exercício de empatia, de tentar calçar os sapatos do outro e entender seus problemas e necessidades.

Conforme Vianna et al. (2011), o Mapa da Empatia consiste em uma síntese das informações sobre o usuário a partir da visualização do que ele diz, faz, pensa e sente. Desse modo, organizam-se os dados da observação de forma a prover entendimento de situações de contexto, comportamentos, preocupações e até aspirações do usuário (ou outros atores estudados). Os autores argumentam que este é um recurso útil quando se tem muita informação de campo e é preciso organizá-la para gerar um melhor entendimento deste público-alvo, de forma a ganhar empatia.

Para Osterwalder e Pigneur (2010), esta ferramenta é um eficiente analisador de usuários, uma vez que favorece entender detalhadamente o que esta pessoa está disposta a adquirir e quanto isso significa para ela.

Portanto, a partir da delimitação do problema e da escolha da ferramenta, entrevistamos seis professores atuantes no Ensino Fundamental II e, com base nas respostas obtidas, organizamos um Mapa da Empatia para possibilitar melhor compreensão a respeito das vivências docentes, contemplando também as principais queixas e necessidades dos professores, visando entender qual o perfil do público contemplado pela proposta de ressignificação (SOUZA, 2017). Nesse sentido, a ressignificação consiste no aprimoramento de algumas características presentes nas práticas de revisão, de acordo com oportunidades identificadas nesta pesquisa.

Os professores entrevistados responderam às seguintes questões: nos aspectos que tangem principalmente a sua prática docente e vida profissional, o que você (1) ouve; (2) vê; (3) pensa e sente; (4) fala e faz; quais são (5) suas principais preocupações e dores e (6) seus objetivos?

A utilização do Mapa da Empatia foi fundamental para entender como fatores de ordem interna e externa impactam a realização da prática docente. Esta ferramenta possibilitou um olhar mais atento para tais fatores, que influenciaram diretamente a elaboração da proposta de uso do Kahoot, visando maior adequação às necessidades desse grupo.

Uma vez que tais levantamentos foram realizados, apresentamos algumas sugestões de utilização do Kahoot com base nas necessidades identificadas. Os seis docentes entrevistados atuam no Ensino Fundamental II em escolas do município do Rio de Janeiro, sendo que dois atuam na rede pública e quatro trabalham na rede privada.

\section{Resultados}

Através da confecção do Mapa da Empatia, constatou-se que professores de Ensino Fundamental II, atuantes do sexto ao nono ano, demonstram crescente preocupação com o equilíbrio entre a vida pessoal e profissional, causado pela alta demanda profissional que vivem, com quatro dos docentes trabalhando em pelo menos duas escolas e, para três deles, em três turnos. As respostas dos professores entrevistados demonstraram também preocupações com fatores como economia 
e segurança, além de aspectos do núcleo familiar que impactam diretamente em seus projetos de vida e, por conseguinte, em sua carga horária de trabalho.

Tais fatores interferem tanto na qualidade de vida dos professores quanto na qualidade do trabalho realizado em sala de aula. Levando em consideração fatores como a instabilidade econômica, a falta de segurança e a vontade de oferecer melhores condições de vida para suas famílias, tais professores assumem cada vez mais responsabilidades profissionais para arcar com suas despesas. Com o aumento da carga de trabalho, torna-se mais difícil desenvolver outras estratégias didáticas e propor novas metodologias para o trabalho em sala de aula. Isso impacta diretamente na utilização de tecnologias digitais no ambiente escolar, pois seu uso demanda tempo de pesquisa e aprendizado para o manuseio dos recursos. Além disso, com o aumento de informações disponíveis em meios como a internet, muitos têm questionado o papel do professor diante de tais mudanças e até mesmo sua relevância, como afirma Libâneo (2013).

Tais circunstâncias evidenciam o período crítico que muitos professores têm enfrentado. Com base nos levantamentos realizados para a organização do Mapa da Empatia e tendo em vista que o Kahoot possui recursos que podem auxiliar os professores no desempenho de sua prática docente e que contemplam alguns aspectos levantados durante as entrevistas, propõe-se uma ressignificação da prática de revisão que contemple as questões levantadas pelos docentes através do uso da plataforma Kahoot, cujas principais funcionalidades serão apresentadas a seguir. No escopo deste trabalho, analisaremos apenas a utilização da modalidade clássica, também conhecida como Kahoot Clássico.

\section{Discussão}

Considerando as necessidades demonstradas pelos docentes entrevistados dispostas no Mapa da Empatia, identificamos possibilidades de trabalho que possam atender a prática docente no Ensino Fundamental II, de modo a incorporar a utilização de tecnologia em sala de aula de uma maneira lúdica e de simples utilização e manutenção para os professores e que, ainda assim, possa auxiliá-los tanto na prática de revisão quanto na avaliação como um processo contínuo da prática docente.

Tendo em vista que o principal fator mencionado nas entrevistas foi a pouca disponibilidade de tempo dos docentes, buscamos no Kahoot algumas possibilidades de utilização da ferramenta que acomodem essa necessidade de elaborar atividades de revisão que promovam maior interesse e engajamento nos alunos e que sejam de fácil manutenção e utilização para que os professores possam utilizá-las frequentemente sem ocasionar em grandes disrupções em suas rotinas e práticas docentes.

Um recurso muito importante que leva em consideração a questão do tempo de planejamento e preparo das aulas é o banco de atividades disponível no Kahoot, cuja importância é destacada por Graham (2015). Todas as atividades produzidas no Kahoot podem ser disponibilizadas para que outros docentes possam reutilizá-las, até mesmo adaptando-as para as suas necessidades pedagógicas. Ao proporcionar tais recursos para professores, o Kahoot possibilita economia de tempo na elaboração de atividades de qualidade. Das quase 120 mil atividades disponíveis em português no Kahoot, cerca de 70 mil delas são voltadas para séries da Educação Básica e abordam temas diversos.

Além de contar com uma vasta gama de atividades, o Kahoot é uma ferramenta pedagógica que possui diversos aspectos positivos para ampliar a participação e interesse dos alunos, afirmam Prá, Freitas e De Araújo Amico (2017). No estudo realizado por essas autoras, professores que utilizaram o Kahoot em suas aulas observaram maior engajamento dos alunos e também constataram que suas aulas se tornaram mais divertidas com a incorporação de atividades do Kahoot. Tais resultados se justificam principalmente no que tange a discentes do Ensino Fundamental II. Por esses alunos estarem no início da adolescência, torna-se fundamental incorporar aspectos como socialização e recompensa na sala de aula, levando-se em consideração as transformações químicas e estruturais pelas quais seus cérebros passam durante esta etapa do desenvolvimento (HERCULANO-HOUZEL, 2005). Nesse sentido, a utilização do Kahoot Clássico e das ferramentas oferecidas no jogo, como a pontuação atribuída por tempo de resposta e do ranking, podem ser componentes favoráveis a tais estímulos.

Todavia, Prá, Freitas e De Araújo Amico (2017) também alertam que tais aspectos podem influenciar negativamente a experiência de aprendizagem. Embora o Kahoot seja uma ferramenta que dispõe de muitos recursos e funcionalidades, deve-se lembrar que a forma de apropriação da ferramenta e do que ela oferece é uma componente fundamental da experiência de uso. Portanto, faz-se necessária a mediação docente para identificar possíveis problemas como competitividade excessiva, trapaça e outros comportamentos negativos e trabalhar ativamente formas de evitar e prevenir tais comportamentos. 
Por exemplo, se todas as atividades realizadas com Kahoot forem sempre de cunho individual, isso pode estimular a competição individualista em um ambiente de aprendizagem. Porém, se os docentes estimularem a formação de grupos para a realização das atividades, os alunos poderão discutir coletivamente as soluções, trabalhando de forma colaborativa.

A mesma linha de pensamento se faz presente ao levar em consideração o formato do jogo: embora a utilização de uma atividade de perguntas e respostas objetivas, em que há apenas uma alternativa correta para cada questão tenha aspectos negativos, é possível se apropriar positivamente do formato. Por exemplo, elaborando questões que levem os alunos à reflexão ao invés de estimular a simples memorização e repetição de conceitos. Além disso, é fundamental aproveitar os momentos pedagógicos que surgem durante a atividade, relembrando resumidamente os conceitos que apóiam a resolução das questões logo após a revelação da resposta correta. Também é possível estimular a colaboração dos próprios alunos nestes momentos, instigando-os a refletir por que determinada resposta é a correta e as outras não e, caso eles se sintam confortáveis, é possível também incentivá-los a compartilhar tais reflexões com a turma.

Sem a devida mediação, nenhum recurso tem a capacidade de, sozinho, modificar um processo complexo de aprendizagem. A proposta de utilização do Kahoot no momento da revisão consiste na inserção do jogo como uma atividade norteadora para a prática pedagógica, mas que não se sustenta sozinha. Desse modo, é muito importante a mediação e a intervenção cuidadosas dos docentes para que seja possível tirar o maior proveito do recurso oferecido.

Outra questão diretamente relacionada à disponibilidade de tempo envolve a avaliação da aprendizagem dos alunos. Muitas vezes, durante o andamento da aula, os professores identificam dificuldades encontradas por alunos, assim como confusões entre conceitos semelhantes, mas, devido à duração dos tempos de aula, acaba não registrando tais observações, que tendem a ser esquecidas com o passar do tempo. Uma funcionalidade disponibilizada pelo Kahoot que pode auxiliar tais aspectos é a geração automática de planilhas de desempenho para a realização de cada atividade.

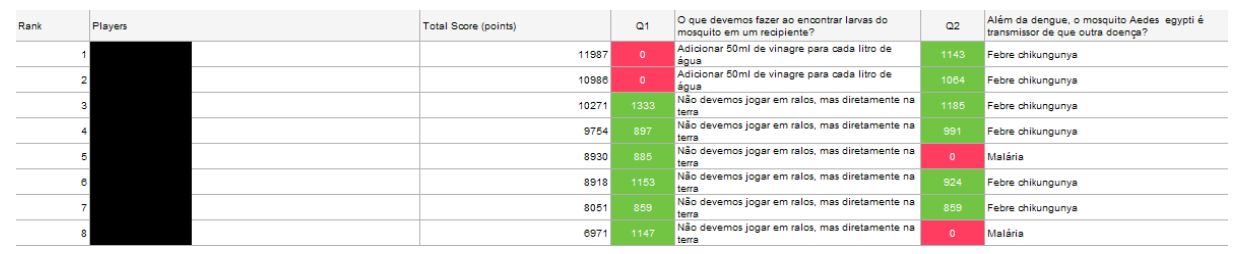

Figura 5: Exemplo de planilha com detalhamento individualizado dos erros e acertos. Essa planilha é gerada automaticamente pelo Kahoot ao final de cada atividade e fica disponível no site para download ou exportação para o Google Drive. Fonte: Bianca Melo.

Todas as estatísticas de erros e acertos são disponibilizadas em planilhas para que o professor possa analisar tais dados posteriormente. Um exemplo de planilha pode ser visto na Figura 5. Tendo em vista que muitos dos profissionais entrevistados para a elaboração do Mapa da Empatia mencionaram pouca disponibilidade de tempo para elaborar planejamentos e novas estratégias didáticas, ter acesso às estatísticas de desempenho dos alunos nas atividades é algo importante. Além de ser uma forma de registro da atividade, isso também possibilita que o professor foque na mediação da turma e na identificação de momentos pedagógicos durante a atividade, sem prejudicar o registro. As planilhas são organizadas para possibilitar análises tanto de alunos específicos quanto da turma como um todo.

\section{Considerações finais}

Considerando-se o que foi exposto neste trabalho, a utilização da ferramenta Kahoot para a prática de revisão possui diversos aspectos positivos. Todavia, faz-se necessária a mediação docente para que seja possível extrair o máximo de benefícios durante a apropriação e incorporação do Kahoot à prática docente.

Também é importante ressaltar que, embora o objetivo da ferramenta seja facilitar a utilização de tecnologia no ambiente escolar, ela demanda uma infraestrutura que não necessariamente está disponível em todas as escolas, como projetor e acesso à internet. 
Espera-se em trabalhos futuros um aprofundamento maior em relação aos recursos e possibilidades disponíveis nas outras modalidades oferecidas pelo Kahoot e identificar oportunidades de utilização da ferramenta em outras práticas do cotidiano docente, como a avaliação.

Em última análise, acredita-se que a utilização do Kahoot pode trazer diversos benefícios para a aprendizagem, dinamizando o processo de revisão de conteúdos e enfatizando o protagonismo discente.

\section{Referências Biliográficas}

ALMEIDA, Maria Elizabeth Bianconcini. Tecnologia na escola. 2015. [online]

ALVES, Nuno de Almeida et al. TIC no Ensino Secundário: usos e mediações. In: Forum Sociológico. Série II. CESNOVA, 2013. p. 87-95.

DELLOS, Ryan. Kahoot! A digital game resource for learning. International Journal of Instructional Technology and Distance Learning, v. 12, n. 4, p. 49-52, 2015.

DETERDING, Sebastian et al. From game design elements to gamefulness: defining gamification. In: Proceedings of the 15th international academic MindTrek conference: Envisioning future media environments. ACM, 2011. p. 9-15.

FORMIGA, Maria do Carmo da Silva et al. A educação digital na Escola Estadual de Ensino Médio "Monsehor Vicente Freitas" - Pombal-PB. 2015.

GRAHAM, Krista. TechMatters: Getting into Kahoot!(s): Exploring a game-based learning system to enhance student learning. LOEX Quarterly, v. 42, n. 3, p. 4, 2015.

HERCULANO-HOUZEL, Suzana. Cérebro Em Transformação, O. Editora Objetiva, 2005.

JUNIOR, João Batista Bottentuit. O aplicativo Kahoot na educação: verificando os conhecimentos dos alunos em tempo real. 2017.

KALETA, Robert; JOOSTEN, Tanya. Student response systems. Research Bulletin, n. 10, 2007.

LIBÂNEO, José Carlos. Adeus professor, adeus professora? Novas exigências profissionais e profissão docente. São Paulo: Cortez, 2013.

OSTERWALDER, A.; PIGNEUR, Y. Business model generation: Handbook for visionaries, game changers and challengers. Hoboken, New Jersey: Wiley; 1 ed., 2010.

PRÁ, Raquel; FREITAS, Tainá Araújo; DE ARAUJO AMICO, Marcia Regina. Análise da Ferramenta Kahoot Como Facilitadora do Processo de Ensino Aprendizagem. Redin-Revista Educacional Interdisciplinar, v. 6, n. 1, 2017.

SANTAELLA, Lucia. Desafios da ubiquidade para a educação. Revista Ensino Superior Unicamp, v. 9, p. 19-28, 2013.

TODOR, Roberto. Taxonomia de Games Educativos. 2015. Dissertação (Mestrado em Design) - Departamento de Artes e Design, Pontifícia Universidade Católica do Rio de Janeiro, Rio de Janeiro.

VIANNA, Maurício et al. Design Thinking inovação em negócios. - Rio de Janeiro: MJV Press, 2012. 162p.

WERNER, Joseane Reis et al. O OBJETO DE APRENDIZAGEM E SUA CONTRIBUIÇÃO NA EDUCAÇÃO. Seminário Institucional do PIBID UNISC, v. 1, n. $1,2015$.

\section{Contato dos autores}

Bianca Joaquim Albuquerque de Melo | bjam.prof@gmail.com

Bruno de Sousa Vieira | vieirasousabruno2@gmail.com

Thalita Martins Rocha | thalita.mrocha@yahoo.com.br

Bianca Martins | bmartins@unicarioca.edu.br

Victor Freitas | vfreitas@unicarioca.edu.br 